\title{
Sense- and antisense-mediated resistance against Sri Lankan cassava mosaic virus (SLCMV) in Nicotiana benthamiana
}

\author{
A. GOGOI ${ }^{1,2,3}$, A. KALDIS ${ }^{2}$, I. DASGUPTA ${ }^{3, *}$, B.K. BORAH ${ }^{1, *}$, A. VOLOUDAKIS ${ }^{2, *}$ \\ Department of Agricultural Biotechnology, Assam Agricultural University, Jorhat, Assam, India ${ }^{1}$ \\ Laboratory of Plant Breeding and Biometry, Department of Crop Science, Agricultural University of Athens, \\ Athens, Greece ${ }^{2}$ \\ Department of Plant Molecular Biology, University of Delhi, South Campus, New Delhi, India ${ }^{3}$
}

\begin{abstract}
Sri Lankan cassava mosaic virus (SLCMV) is the principal causal agent of cassava mosaic disease in the Indian subcontinent. To gain resistance against the virus, the coat protein $(C P)$ gene, namely the $A V 1$ of SLCMV-Adivaram isolate, was cloned in either sense or antisense orientation under the Cauliflower mosaic virus 35S promoter, and transgenic Nicotiana benthamiana plants were obtained through Agrobacterium-mediated transformation. A total of eight $\mathrm{T} 1$ transgenic lines, four harboring the $C P$-sense construct and four harboring the $C P$-antisense construct were challenged with agro-infectious clones of SLCMV DNA-A and DNA-B. Based on symptom exhibition at 20 days post inoculation, 3 out of the $4 C P$-sense transgenic lines and all $4 C P$-antisense transgenic lines showed a high level of resistance against SLCMV. In addition, a delay in symptom initiation was observed in all the transgenic lines inoculated with a high viral load at agro-dilution 1:625 from an absorbance $\left(\mathrm{A}_{600}\right)$ of 1 . However, the resistance was more prominent at a lower viral load of 1:1000 agro-dilution. The viral titer was lower in the SLCMV-challenged transgenic lines compared to the non-transgenic $N$. benthamiana plants as confirmed by quantitative PCR and dot blot analysis. Furthermore, small RNA Northern blot analysis revealed lowered amounts of virus-specific small interfering RNAs in the resistant transgenic lines as compared to the non-transgenic plants upon SLCMV infection, which correlates to lower virus titers due to resistance against the virus.
\end{abstract}

Additional key words: coat protein gene, RNAi, RNA silencing, vsiRNAs

\section{Introduction}

Geminiviruses (family: Geminiviridae) is the largest group of plant viruses possessing a circular single-stranded DNA genome, which is encapsidated into incomplete twinned icosahedral particles (Fauquet et al. 2008, Ramesh et al. 2017). According to ICTV, the family Geminiviridae comprises nine genera: Becurtovirus, Begomovirus, Capulavirus, Curtovirus, Eragrovirus, Grablovirus, Mastrevirus, Topocuvirus, and Turncurtovirus; classified based on genome organization and vector transmission.
The genus Begomovirus has the largest number of members, which infect mostly dicots and are mainly transmitted by whitefly (Bemisia tabaci) and possess either a monopartite (a single DNA component) or bipartite (two DNA components) genome (Borah and Dasgupta 2012). Sri Lankan cassava mosaic virus (SLCMV) belongs to the genus Begomovirus and has two genomic components (DNA-A and DNA-B) (Saunders et al. 2002). Cassavainfecting begomoviruses that cause Cassava Mosaic Disease (CMD) include several viruses; among them, SLCMV is most prevalent and devastating one in the

Submitted 14 July 2018, last revision 13 December 2018 acccepted 2 January 2019.

Abbreviations: $\mathrm{A}_{600}$ - absorbance at $600 \mathrm{~nm}$; CMD - Cassava mosaic disease; CP - coat protein; dNTPs - deoxy nucleotide triphosphate; dpi - days post inoculation; dsRNA - double-stranded RNA; LB - Luria-Bertani; MES - 2-(N-Morpholino)ethanesulfonic acid hydrate; MS - Murashige and Skoog; NbNt - Nicotiana benthamiana non-transgenic; PDR - pathogen-derived resistance; PTGS - posttranscriptional gene silencing; qPCR - real-time quantitative PCR; RDR - RNA-dependent RNA polymerase; RNAi - RNA interference; siRNA - small interfering RNA; SLCMV - Sri Lankan cassava mosaic virus; vsiRNA - virus-specific small interfering RNA.

Acknowledgments: The European Commission (EACEA) for providing Erasmus Mundus BRAVE (Grant 2013-2536/001-001) is acknowledged for the fellowship to AG. In addition, AG was supported by funds as a Junior Research Fellow at the University of Delhi, South Campus (UDSC), India. Kanika Gupta from the UDSC is acknowledged for her technical support in sowing the $\mathrm{T}_{1} N$. benthamiana seeds for the challenging experiment. Ashish Kumar Singh from the Jawaharlal Nehru University (JNU), India, and Gaurav Kumar from the UDSC are acknowledged for their technical support in small RNA Northern blot. The authors also acknowledge the support of Prof. Supriya Chakraborty, JNU, for allowing AG to do a part of the Northern blot work in his lab.

*Corresponding authors; e-mail: avoloud@aua.gr, basantabora@gmail.com, indrani158@yahoo.co.in 
Indian subcontinent (Patil and Fauquet 2009).

Cassava (Manihot esculenta Crantz, family Euphorbiaceae) is the third most important source of carbohydrates in the tropics, after rice and maize, and more than 800 million people use cassava as a staple food crop in Africa, Asia, and Latin America (Alabi et al. 2011). In addition, cassava feedstock can be used for an efficient bioethanol production and income generation (Nguyen et al. 2007, Nuwamanya et al. 2012); the crop acts as a renewable energy source for biofuel economy. Most cassava cultivars are prone to CMD resulting in a tremendous loss in cassava production. In particular, the total storage root-yield loss due to CMD is estimated to be 12-23 million tons annually or US\$ 1.2 to 2.3 billion across Sub-Saharan Africa (Thresh et al. 1997). The CMD is characterized by symptoms such as a mosaic, mottling, curling, vein hardening, twisted leaflets, and an overall reduction in tuber growth and leaf size (Alabi et al. 2011, Ntui et al. 2015).

Several control strategies have been used against CMD; such approaches include improved cultural practices, control of insect-vectors, use of CMD resistant varieties and engineering resistance through RNA interference (RNAi) (Thresh and Cooter 2005). Management of the whitefly (B. tabaci) insect-vector is an indirect strategy to control the spread of cassava-infecting begomoviruses. Both protein-based and RNAi-based approaches have been found successful to control geminivirus-transmitting whiteflies (Thakur et al. 2014, Raza et al. 2016, Shukla et al. 2016). Recently, a non-transgenic strategy of doublestranded RNA (dsRNA) application aiming at whitefly control has been suggested by Gogoi et al. (2017). Genetic engineering of cassava using RNA silencing against African cassava-infecting geminiviruses has been successful in the past two decades (reviewed by Vanderschuren et al. 2007b).

Ribonucleic acid silencing (or RNA interference, RNAi) has been proven as an important antiviral defense mechanism in plants (Baulcombe 2004, Fukunaga and Doudna 2009, Vanderschuren et al. 2007a). Upon plant viral infection, aberrant viral transcripts are converted into double-stranded (ds) RNA molecules by host RNAdependent RNA polymerases (RDRs). These dsRNAs are subsequently processed into small interfering RNAs (siRNAs) of varying length (21-24 nucleotides) by the Dicer-like proteins. These siRNAs can direct sequencespecific degradation of target viral transcripts to promote antiviral silencing in plants. Several lines of evidence, coming from the studies of siRNAs and viral pathogenesis (Wang et al. 2012, Peláez and Sanchez 2013), have led to the understanding of cytoplasmic RNA silencing, also referred to as post-transcriptional gene silencing (PTGS). The PTGS acts as a ubiquitous plant defense response against most RNA-viruses and transcripts produced by DNA-viruses such as geminiviruses.

There are mainly three approaches of pathogen-derived resistance (PDR) for obtaining genetically engineered resistance against plant viruses (Baulcombe 1996). Firstly, a complete or partial viral (sense) gene is introduced into the plant nuclear genome, which is either translated into a protein or transcribed into an aberrant RNA molecule in the plant cell. As a result, it interferes with viral multiplication and pathogenesis in the host system rendering the transgenic plants tolerant to viral infection (de Haan 1998). Virus-resistant transgenic plants have been developed in several crops by introducing viral sequences encoding coat protein (CP) (Abel et al. 1986, Raj et al. 2005, Srivastava and Raj 2008), which is conventionally called Coat Protein-Mediated Resistance (CP-MR). The use of viral $C P$ as a transgene for developing virusresistant plants was a great accomplishment in the field of plant biotechnology. Secondly, engineering for viral resistance could use the concept of antisense-mediated gene silencing (Serio et al. 2001), where antisense viral transcripts are allowed to express in engineered plants. The presence of antisense viral transcripts is suggested to lead to the formation of dsRNAs with the complementary sense transcripts produced by plant viruses upon infection. The dsRNAs, in turn, elicit the RNA silencing machinery and provide substantial resistance against most geminiviruses (Bejarano and Lichtenstein 1994, Yang et al. 2004, Haq et al. 2010, Amudha et al. 2011, Sohrab et al. 2016). Thirdly, a hairpin RNA encoding sense and antisense sequences in a single transcript is expressed producing a dsRNA in transgenic plants conferring resistance to the cognate virus upon viral infection (Hu et al. 2011, Leibman et al. 2011, Aslam et al. 2018).

In the present study, we engineered Nicotiana benthamiana plants to express the full-length transcripts of the SLCMV CP gene in either sense or antisense orientation. We report that transgenic $N$. benthamiana lines were found to be resistant to SLCMV suggesting that these two constructs could be used to engineer resistance to SLCMV in elite cassava cultivars for food and non-food (biofuel) purposes.

\section{Materials and methods}

Cloning and bacterial transformation: The SLCMV[Ker20] segment A of isolate Adivaram (Genbank accession no. AJ579307.1) that was previously cloned into a TOPO cloning vector (Dutt et al. 2005) was used as a PCR template. For the amplification of the SLCMV CP ( $A V 1)$ gene, In-fusion sense primers were designed (Table 1 Suppl.) and cloning was performed using an In-Fusion ${ }^{\circledR}$ HD Cloning Kit (Clontech, USA, Fig. 1A). For the antisense$C P$ construct, forward and reverse primers were designed with $\mathrm{SacI}$ and BamHI restriction sites, respectively, (Table 1 Suppl.) and cloned in the antisense orientation in a pBI121 vector (Fig. $1 B$ ). For PCR, $\sim 100 \mathrm{ng} / \mu 1$ of template DNA was used in a total reaction volume of $20 \mu \mathrm{l}$ using an Eppendorf Master Cycler (Eppendorf, UK). The reaction consisted of 1X KAPA Taq A buffer (KAPA Biosystems, South Africa), $200 \mu \mathrm{M}$ dNTPs, $0.4 \mu \mathrm{M}$ forward (SLCMV CPs_1_pBI121_InFusion/SLCMV_CPas_SacI-F) and reverse (SLCMV_CPs_771_pBI121_InFusion/SLCMV CPas_BamH1-R) primers, and 0.4 U KAPA Taq DNA polymerase (KAPA Biosystems, South Africa). Conditions for PCR were set at $94{ }^{\circ} \mathrm{C}$ for 5 min followed by 34 cycles 

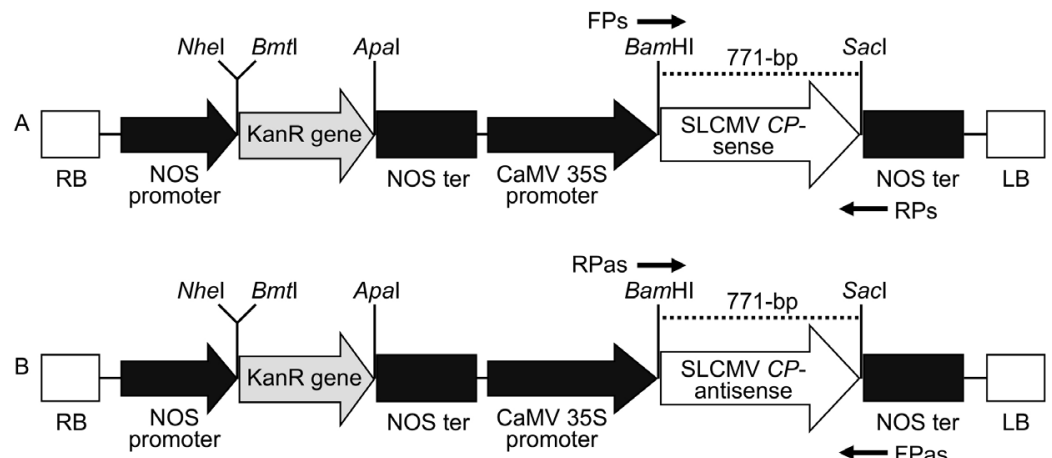

Fig. 1. Schematic representation of the recombinant binary constructs harboring Sri Lankan cassava mosaic virus coat protein (SLCMV CP) gene. $A$ - The PCR amplified SLCMV CP gene (771 bp) was cloned in sense orientation in a pBI121 vector under the control of the cauliflower mosaic virus (CaMV) 35S promoter flanked by Bam HI and SacI restriction sites. $B$ - The PCR amplified SLCMV CP gene (771 bp) was cloned in antisense orientation in pBI121 under the control of CaMV 35S promoter flanked by BamHI and SacI restriction sites. The thick black arrows indicate forward (FPs and FPas) and reverse (RPs and RPas) primers used for amplification and detection of transgene in transgenic lines (see Figs. 1-3 Suppl.).

of $94{ }^{\circ} \mathrm{C}$ for $30 \mathrm{~s}, 55^{\circ} \mathrm{C}$ for $30 \mathrm{~s}, 72^{\circ} \mathrm{C}$ for $1 \mathrm{~min}$, and then a final extension for $7 \mathrm{~min}$.

For bacterial transformation, Escherichia coli competent cells (Invitrogen, USA) were used for transforming sense- and antisense- $C P$ constructs. Positive colonies were selected on Luria-Bertani (LB) Agar (50 mg/L kanamycin) and positive clones were further confirmed by colony PCR, restriction digestion, and finally by Sanger sequencing (Beckman Coulter, UK) (Fig. 1 Suppl.).

\section{Mobilization of CP-sense and CP-antisense} constructs into Agrobacterium tumefaciens and plant transformation: Both the sense- and antisense$C P$ constructs were mobilized into electro-competent Agrobacterium tumefaciens $\mathrm{C} 58 \mathrm{C} 1$ cells. Electroporation was performed using MicroPulser ${ }^{\mathrm{TM}}$ Electroporator (Bio-RAD, USA) at $2.2 \mathrm{kV}$ for $5.8 \mathrm{~ms}$. A hundred microliters of transformed Agrobacterium cells was spread onto a LB agar plate containing $50 \mathrm{ml} / \mathrm{L}$ kanamycin and incubated at $28^{\circ} \mathrm{C}$ for 2 days.

For Agrobacterium-mediated plant transformation, bacterial suspension cells were cultured in LB broth $(50 \mathrm{mg} / \mathrm{L}$ kanamycin) and incubated overnight in an orbital shaker $\left(200 \mathrm{~min}^{-1}\right)$ at $28^{\circ} \mathrm{C}$. Bacterial cells were pelleted at 2,000 $\mathrm{g}$ for $20 \mathrm{~min}$, re-suspended, and diluted to an absorbance $\left(\mathrm{A}_{600}\right)$ of 1 in a liquid MS (Murashige and Skoog 1962) resuspension medium [MS including vitamins (4.4 g/L), sucrose $30 \mathrm{~g} / \mathrm{L}, \mathrm{pH}$ 5.8] containing $100 \mu \mathrm{M}$ acetosyringone.

For plant transformation, young $N$. benthamiana leaf discs were used as a starting material and a standard transformation protocol was followed as described by Pathi et al. (2013) with minor modifications. Leaf discs were co-cultured with the Agrobacterium cells harboring the sense- and antisense- $C P$ constructs nonsimultaneously in MS co-culture medium [MS including vitamins $(4.4 \mathrm{~g} / \mathrm{L})$, sucrose $30 \mathrm{~g} / \mathrm{L}, \mathrm{pH} 5.8$, agar $8 \mathrm{~g} / \mathrm{L}$, plus $1 \mathrm{mg} / \mathrm{L}$ 6-benzylaminopurine (BAP) and $0.1 \mathrm{mg} / \mathrm{L}$ $\alpha$-napthalene acetic acid (NAA)] without any antibiotics for two days and transferred to a MS selection medium [including vitamins $(4.4 \mathrm{~g} / \mathrm{L})$, sucrose $30 \mathrm{~g} / \mathrm{L}$, pH 5.8, agar $8 \mathrm{~g} / \mathrm{L}$, plus $1 \mathrm{mg} / \mathrm{L}$ BAP, $0.1 \mathrm{mg} / \mathrm{L} \mathrm{NAA]}$ (10 explants/ plate) with antibiotics $(70 \mathrm{mg} / \mathrm{L}$ kanamycin and $250 \mathrm{mg} / \mathrm{L}$ carbenicillin). Shoots were excised individually once they reached a length greater than $3 \mathrm{~mm}$ and transferred to a rooting medium [MS including vitamins $(4.4 \mathrm{~g} / \mathrm{L})$, sucrose $30 \mathrm{~g} / \mathrm{L}, \mathrm{pH} 5.8$, agar $5 \mathrm{~g} / \mathrm{L}$ ] supplemented with antibiotics (70 mg/L kanamycin and $250 \mathrm{mg} / \mathrm{L}$ cefotaxime). For rooting, the same growth conditions as the regeneration step were used; roots were established within two weeks and the rooted plantlets were transferred to soil for hardening. For screening the transformed explants, genomic DNA was isolated from the $N$. benthamiana leaves using a modified Dellaporta protocol (Dellaporta et al. 1983) and positive explants were confirmed by PCR in the $\mathrm{T}_{0}$ and $\mathrm{T}_{1}$ transgenic lines (Fig. 2 Suppl., Fig. 3 Suppl.).

Challenging transgenic $N$. benthamiana plants by Agro-infection of SLCMV: The PCR-positive plants from the segregated $\mathrm{T}_{1}$ transgenic lines were tested for viral resistance using agro-infectious clones of SLCMV DNA-A and DNA-B. Single colonies of Agrobacterium cells harboring the SLCMV DNA-A and DNA-B as separate clones in pCambia2300_A1.0 and pCambia2300_B1.5, respectively, (Mittal et $\bar{a}$ l. 2008) were cultured in LB broth containing antibiotics $(50 \mathrm{mg} / \mathrm{L}$ each of rifampicin and kanamycin). Ten mililiters of secondary cultures containing the same antibiotics were prepared from each primary culture and incubated at the same conditions until $\mathrm{A}_{600}=1$ was reached. The bacterial cells were pelleted by centrifugation at 2,000 g for $10 \mathrm{~min}$. The cells were then re-suspended in an MS resuspension medium $(10 \mathrm{mM}$ MES hydrate, $10 \mathrm{mM} \mathrm{MgCl}_{2}, 150 \mu \mathrm{M}$ acetosyringone) with two dilutions (1:1000 and 1:625 of a culture having an absorbance $\mathrm{A}_{600}$ of 1$)$. One mililiter of diluted bacterial cells was infiltrated onto young mature $\left(3^{\text {rd }}\right.$ and $\left.4^{\text {th }}\right)$ leaves using a 1-ml needleless syringe.

Observation of disease symptom development and sample collection: Phenotypic observations for symptom appearance on the young systemic leaves were taken 

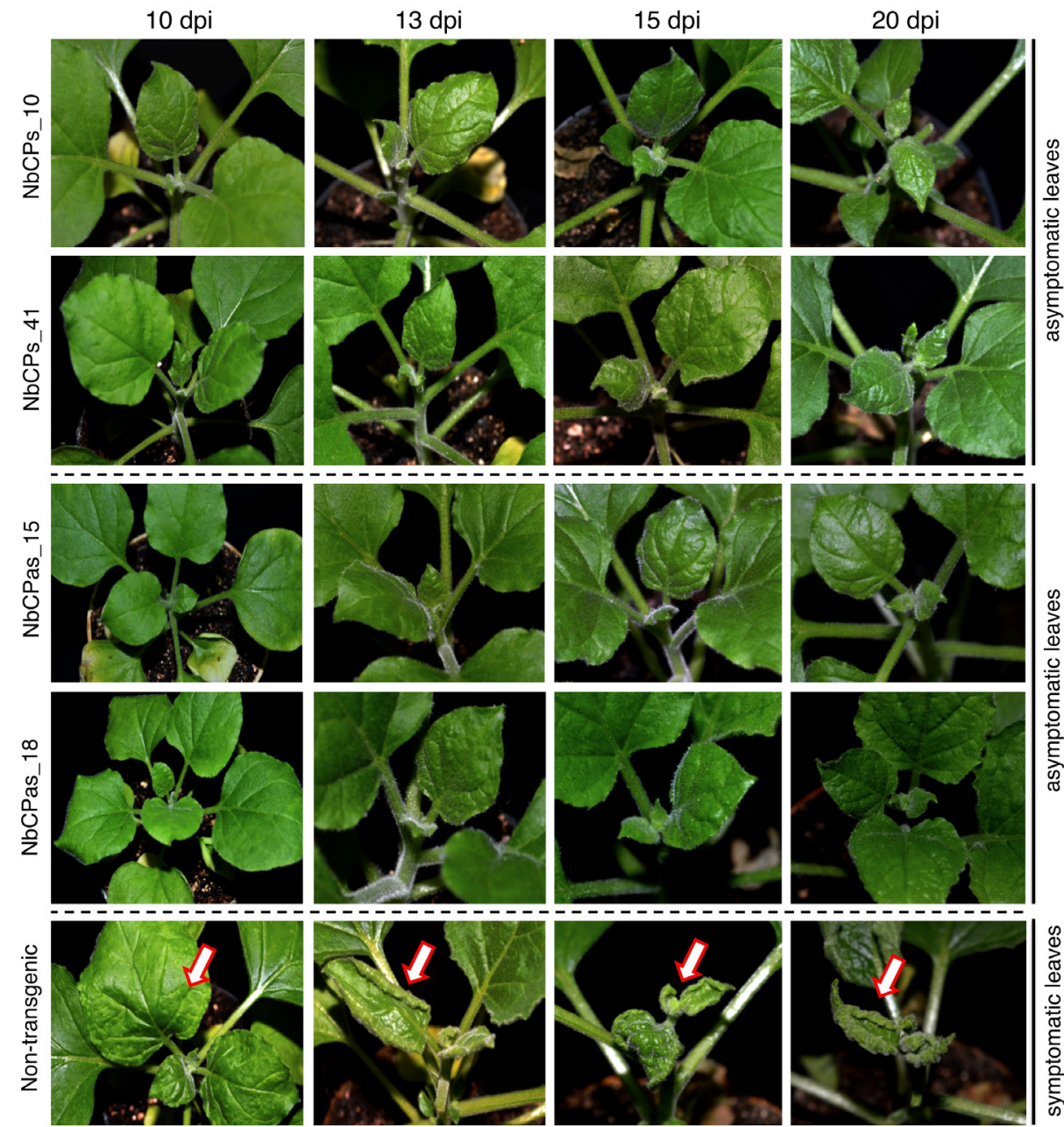

Fig. 2. Phenotypic observation for Sri Lankan cassava mosaic virus (SLCMV) infection over time at 10-20 days post-inoculation (dpi) in agro-inoculated non-transgenic ( $\mathrm{NbNt}$ ) and transgenic Nicotiana benthamiana lines. Comparison of viral symptoms in $\mathrm{NbNt}$, two asymptomatic transgenic $N$. benthamiana coat protein $(C P)$-sense lines (NbCPs 10 and $\mathrm{NbCPs} 41$ ), and two asymptomatic transgenic $N$. benthamiana $C P$-antisense lines (NbCPas_15 and NbCPas_18). All agro-inoculations were done at 1:625 agro-dilution from an absorbance of 1 . The arrows indicate symptom appearance such as upward leaf curling and vein hardening in inoculated $\mathrm{NbNt}$ plants.

at different time points: 10, 13, 15 and 20 days postinoculation (dpi). Leaf samples were collected at 10, 15 and 20 dpi for DNA isolation to estimate virus titer and at 15 and 20 dpi for total RNA for small RNA analysis.

Quantification of viral DNA: For real-time quantitative PCR (qPCR) of SLCMV, plant genomic DNA was isolated from a bulk sample for each transgenic plant line by a modified DNA isolation Dellaporta protocol; the bulk sample comprised a leaf disc from young systemic leaves of all plants. The total reaction volume of $25 \mu \mathrm{l}$ for each qPCR reaction included $9.5 \mu \mathrm{H}_{2} \mathrm{O}, 1 \mu \mathrm{l}(10 \mu \mathrm{M})$ each of forward and reverse primers, $1 \mu \mathrm{l}(1 \mu \mathrm{g})$ of genomic DNA and $12.5 \mu \mathrm{l}$ of 2x KAPA SYBR ${ }^{\circledR}$ FAST qPCR Master mix Universal (KAPA Biosystems, South Africa). All qPCR reactions were performed in three replicates in Eppendorf Mastercycler $^{\circledR}$ Realplex $^{2}$ and a standard curve for SLCMV DNA-A was constructed for viral copy number estimation using the cloned pCambia2300 A1.0 plasmid to build the standard curve. Elongation factor 1 alpha (EFla, Liu et al.
2012) was used as a loading control. Primers used for the qPCR reactions are shown in Table 1 Suppl.

Dot-blot analysis: Isolated genomic DNA from SLCMV-inoculated $N$. benthamiana plants were spotted on a positively charged Hybond ${ }^{T M}-N^{+}$membrane ( $G E$ Healthcare, USA). A total of $1 \mu \mathrm{g}$ of DNA from each sample was loaded onto the membrane. A Digoxigenin (DIG) 11-dUTP-labeled probe for the SLCMV AC1 (Rep) gene was prepared using DIG High Prime DNA Labeling and Detection Starter Kit II (Roche, Germany). Detection of viral titer was performed according to the manufacturer's instructions.

Small RNA Northern blot analysis: Total RNA was isolated from young systemic leaves of agro-inoculated $N$. benthamiana plants [non-transgenic $(\mathrm{NbNt})$ ] and transgenic) using a modified Guanidine thiocyanate protocol as described by Chomczynski and Sacchi (1987). Small RNAs were enriched using polyethylene 


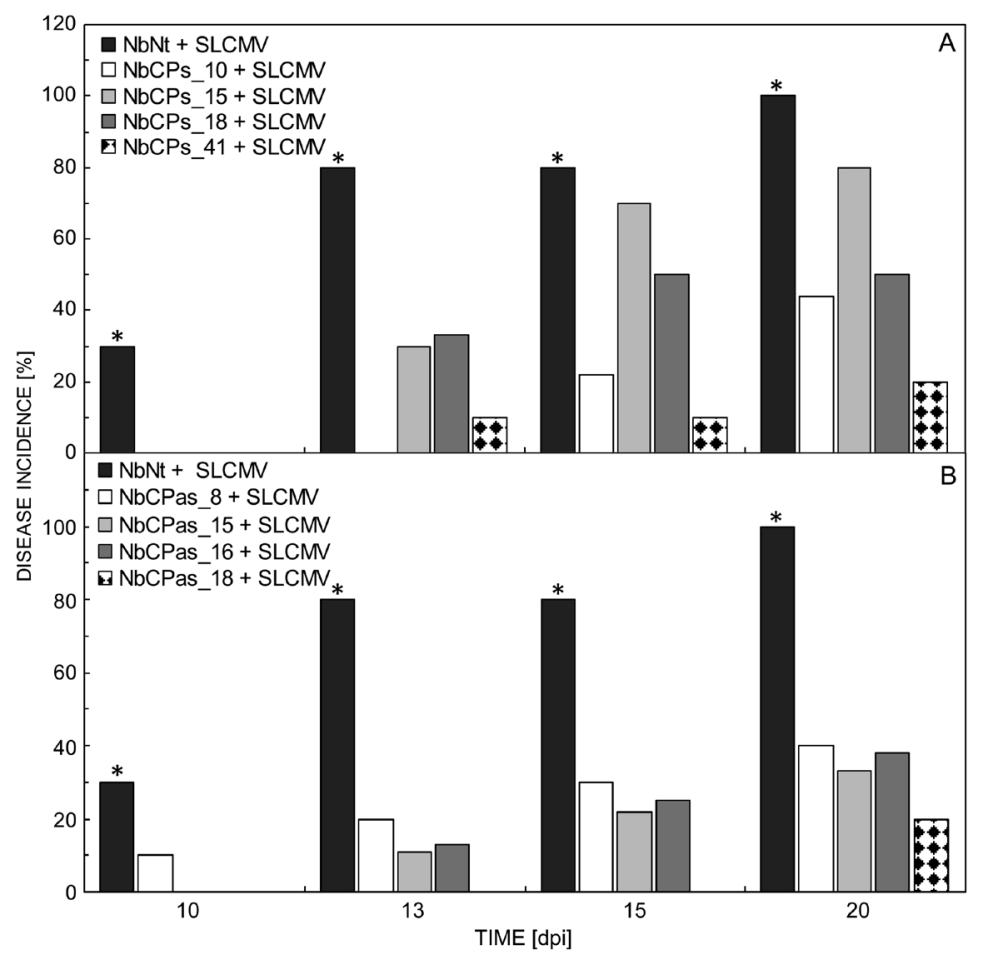

Fig. 3. Disease incidence in non-transgenic $(\mathrm{NbNt})$ and transgenic Nicotiana benthamiana plants challenged with Sri Lankan cassava mosaic virus (SLCMV) at 10-20 dpi. A - The percentage of symptomatic plants of NbNt and transgenic coat protein $(C P)$-sense lines agro-inoculated with SLCMV DNA-A and DNA-B. B - The percentage of symptomatic plants of NbNt and transgenic $C P$-antisense lines agro-inoculated with SLCMV DNA-A and DNA-B. The asterisk indicates that the mean value of disease incidence in the NbNt plants is significantly different from the mean values in the $C P$-sense and $C P$-antisense lines $(\mathrm{P}<0.05$, the Student t-test). All agroinoculations were performed at 1:625 agro-dilution from an absorbance of 1 . The letters $s$ and as in the name of the transgenic line denotes $C P$-sense and $C P$-antisense transgenic $N$. benthamiana lines, respectively.

glycol (MW 8000, Curtin et al. 2012) with minor modifications. Forty micrograms $(10 \mu \mathrm{l})$ of enriched small RNAs were separated by $15 \%$ polyacrylamide gel electrophoresis and transferred to a positively charged Hybond $^{\mathrm{TM}}-\mathrm{N}^{+}$membrane ( $G E$ Healthcare, USA). The transfer was carried out at $35 \mathrm{~V}$ and $4{ }^{\circ} \mathrm{C}$ for 8 hours using Bio-Rad Trans-blot Cell (USA) containing $1 \mathrm{X}$ Tris-Borate-EDTA (TBE) buffer. The membrane

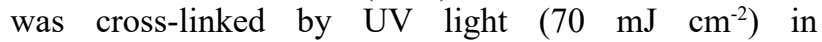
a UVP HL-2000 HybriLinker ${ }^{\mathrm{TM}}$ Hybridization Crosslinker (Fisher Scientific, USA). A radiolabeled $\left(\alpha-\mathrm{P}^{32} \mathrm{dCTPs}\right.$ labeled) SLCMV-CP probe was mixed with a standard pre-hybridization buffer (Sambrook et al. 1989) to hybridize with the $C P$ specific siRNAs. The membrane was incubated at $45^{\circ} \mathrm{C}$ for 48 hours and washed with a washing buffer-I [ $2 \mathrm{X}$ SSC $(0.3 \mathrm{M} \mathrm{NaCl}, 0.03 \mathrm{M}$ sodium citrate) and $0.2 \% \mathrm{~m} / \mathrm{v}$ SDS] and a washing buffer-II [1X SSC and $0.2 \%(\mathrm{~m} / \mathrm{v}) \mathrm{SDS}$ ] for $5 \mathrm{~min}$ each at room temperature. A siRNAs signal was detected using Typhoon FLA 9500 (GE Healthcare, USA).

\section{Results}

Potential transgenic $N$. benthamiana plants were screened by PCR for the presence of the $C P$-sense and $C P$-antisense gene at $\mathrm{T}_{0}$ stage. Seeds from the screened $\mathrm{T}_{0}$ plants were grown for obtaining $\mathrm{T}_{1}$ transgenic lines as confirmed by PCR (Fig. 2 Suppl., Fig. 3 Suppl.).

The NbNt plants inoculated with SLCMV exhibited the characteristic disease symptoms such as upward leaf curling and vein hardening at 10-20 dpi (Fig. 2). In contrast, the $\mathrm{T}_{1}$ transgenic $N$. benthamiana lines harboring the sense- and antisense- $C P$ constructs showed a significant resistance against SLCMV infection at the 1:1000 agro-dilution (Fig. 4 Suppl.). In order to check the level of resistance at a higher viral load due to ambiguous information about the nature of infection in the field, the experiment was repeated with a greater viral load with the agro-dilution 1:625 as mentioned above. A similar resistance phenotype was observed in the challenged transgenic $N$. benthamiana lines compared to the $\mathrm{NbNt}$ infected (Fig. 2). Infected plants were counted based on the observed symptoms at different time points (10-20 dpi), and it was found that the percentage of infection was less in the transgenic $C P$-sense and $C P$-antisense lines than in the NbNt plants (Fig. 3, Fig. 4 Suppl.).

The transgenic $C P$-sense (NbCPs_10, NbCPs_15, NbCPs_18, and NbCPs_41) and $C P$-antisense (NbCPas_8, $\mathrm{NbCPas} 15, \mathrm{NbCPas} \overline{16}$, and NbCPas 18) lines at agrodilution $\overline{1}: 1000$ gave on an average $\overline{82.5} \%$ and $74 \%$ resistance at $20 \mathrm{dpi}$, respectively, when $\mathrm{NbNt}$ exhibited $0 \%$ resistance; the difference in mean values was statistically significant (Fig. 4 Suppl.). These transgenic 


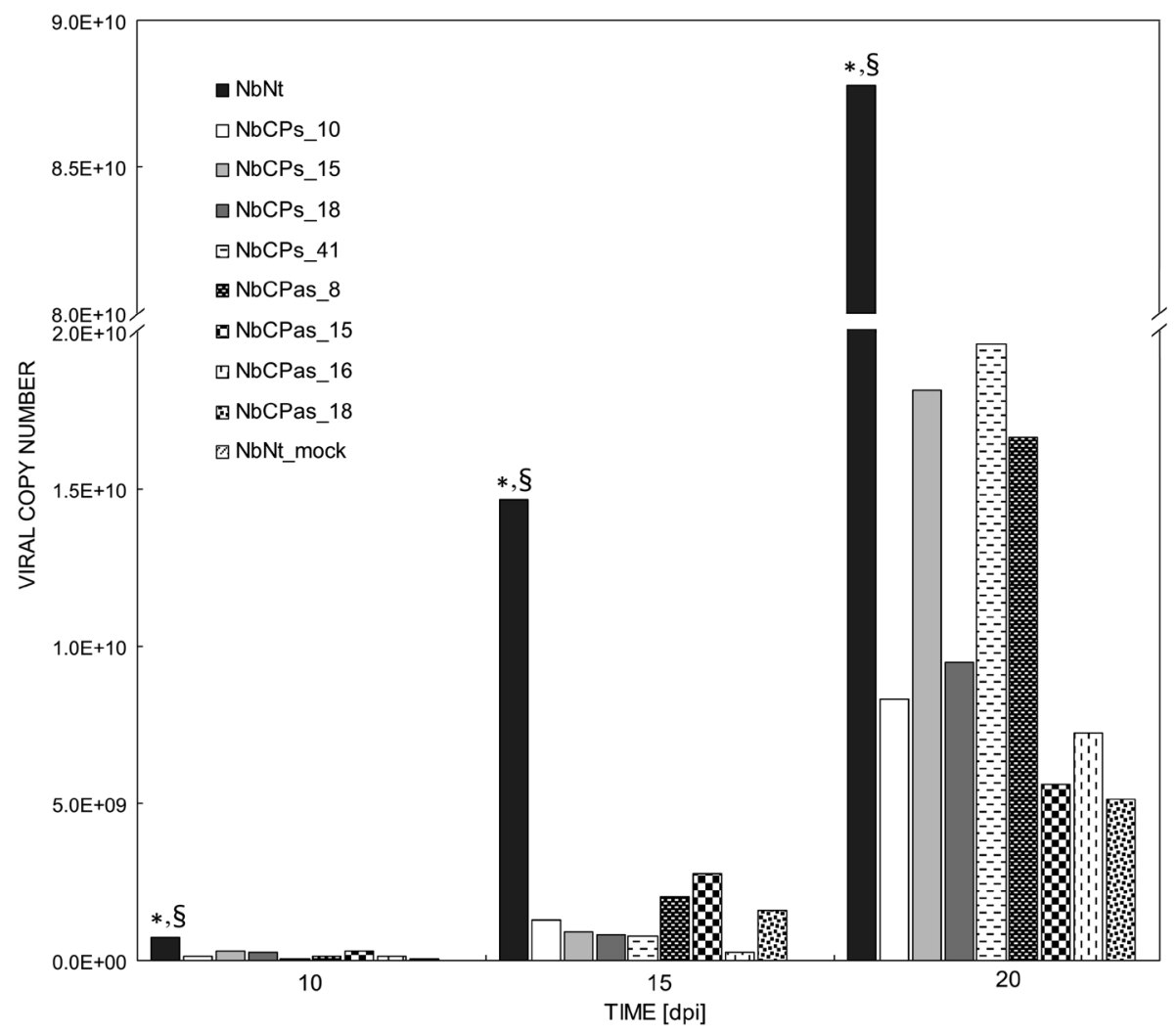

Fig. 4. Estimation of the viral copy number in non-transgenic (NbNt) and transgenic Nicotiana benthamiana lines agro-inoculated with Sri Lankan cassava mosaic virus (SLCMV) DNA-A and DNA-B at 10-20 dpi via quantitative PCR. The DNA isolated from each line was from a bulk sample of 10 individual test plants. Three technical replicates of each sample were taken and a mean cycle threshold (CT) value was considered for calculating the viral copy number using a standard curve of pCambia2300_A1.0 (see Fig. 5 Suppl.). * and $\S$ indicate that the mean value of the viral copy number in the NbNt plants is significantly different from the corresponding mean values in the coat protein $(C P)$-sense and $C P$-antisense lines, respectively, $(\mathrm{P}<0.005$, the Student t-test). Infiltrated Escherichia coli cells harboring SLCMV DNA-A and DNA-B in NbNt plants were considered as mock-inoculated plants. The letters $s$ and $a s$ in the name of the transgenic line denotes $C P$-sense and $C P$-antisense transgenic $N$. benthamiana lines, respectively.

$C P$-sense and $C P$-antisense lines at agro-dilution 1:625 gave on an average $51.5 \%$ and $67.3 \%$ resistance at $20 \mathrm{dpi}$, respectively, when $\mathrm{NbNt}$ exhibited $0 \%$ resistance; the difference in mean values was statistically significant (Fig. 3). Although the antisense lines had a mean value for resistance higher than the sense lines, $t$-test analysis did not prove this difference to be statistically significant. Based on the phenotypic information, the plants of the NbCPs 15 line, surprisingly, did not confer resistance ( $20 \%$ at $20 \overline{\mathrm{dpi}})$ to a comparable level as all other transgenic lines studied. In addition, no symptoms were observed in 7 out of 8 transgenic lines at $10 \mathrm{dpi}$, corresponding to $0 \%$ disease incidence in all 7 transgenic lines with an exception of $10 \%$ in NbCPas 8 (when NbNt plants showed a $30 \%$ disease incidence) indicating a symptom appearance delay (Fig. 3).

In order to determine the viral titer, qPCR was performed using the isolated genomic DNA from SLCMVinoculated $N$. benthamiana plants as a template for PCR. Quantitative PCR was carried out at different time points (10, 15, and $20 \mathrm{dpi})$. A standard curve was prepared using pCambia2300_A1.0 as a template for the qPCR at different dilution points $\left(10^{1}-10^{10}\right.$, Fig. 5 Suppl.). The viral copy number was found to be $4-11$ fold lower in the
$C P$-sense lines and 5-17 fold lower in the $C P$-antisense lines as compared to the $\mathrm{NbNt}$ plants at $20 \mathrm{dpi}$; the difference in mean values was statistically significant (Fig. 4). Furthermore, the viral concentration in the agroinoculated non-transgenic and transgenic $N$. benthamiana lines was checked semi-quantitatively by dot-blot analysis using the DIG labelled SLCMV AC1 (Rep) probe (see Materials and methods). The viral titer was comparatively lower in the challenged transgenic lines than in the NbNt infected plants (Fig. 6 Suppl.).

To understand the mechanism of resistance in the transgenic $N$. benthamiana $C P$-sense and $C P$-antisense lines to SLCMV, small RNA Northern blot analysis was performed to detect virus-specific small interfering RNAs (vsiRNAs) in the inoculated $\mathrm{NbNt}$ and transgenic $N$. benthamiana lines. The vsiRNAs were detected using the radiolabeled SLCMV $C P$ probe at two different time points, namely at 15 and $20 \mathrm{dpi}$. It was found that a vsiRNA signal was more intense in the SLCMV-inoculated $\mathrm{NbNt}$ plants than in all the transgenic $N$. benthamiana lines (Fig. 5). The presence of a more intense signal in the susceptible NbNt plants could be derived from a higher viral load in these plants; the viral load was relatively lower in the transgenic lines (Fig. 4, Fig. 6 Suppl.). 


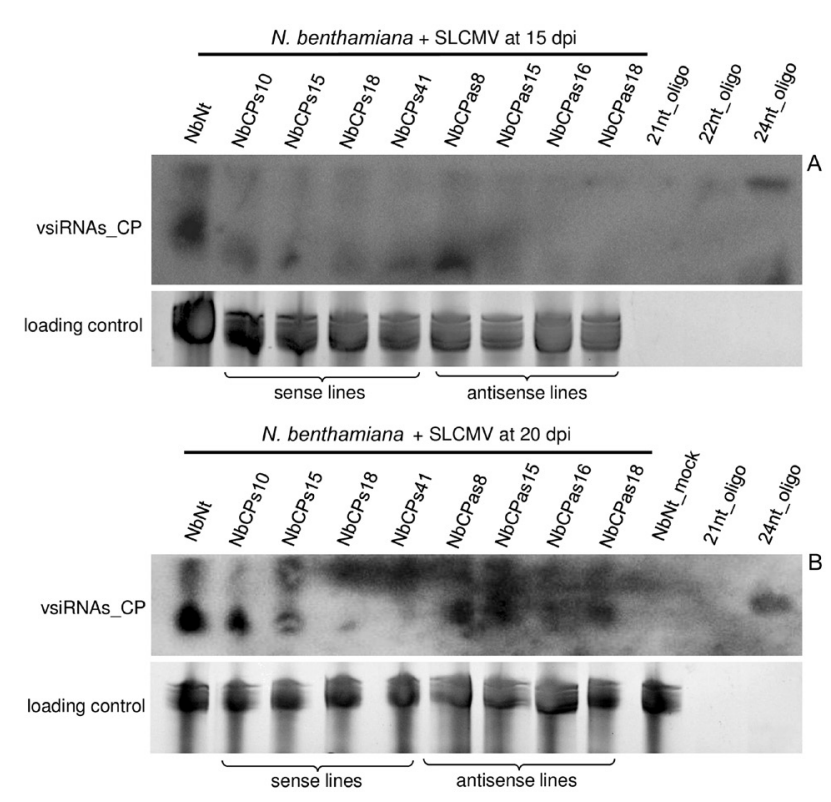

Fig. 5. Accumulation of virus-specific siRNAs (vsiRNAs) in Sri Lankan cassava mosaic virus (SLCMV)-inoculated nontransgenic $(\mathrm{NbNt})$ and transgenic Nicotiana benthamiana lines at A - 15 dpi and B - 20 dpi. Radiolabeled SLCMV coat protein $(C P)$ probe was used to detect vsiRNAs in the NbNt and transgenic $C P$-sense and $C P$-antisense lines. Infiltrated Escherichia coli cells harboring SLCMV DNA-A and DNA-B in NbNt were used as mock-inoculated plants. Ethidium bromide stained total RNA in PAGE gel was used as a loading control. The letters s and as denotes $C P$-sense and $C P$-antisense transgenic $N$. benthamiana lines, respectively. 21nt_oligo, 22nt_oligo, and 24nt_oligo denote low molecular weight markers.

\section{Discussion}

Plant resistance against a viral pathogen using gene segments from the same virus was designated as PDR and has been extensively and successfully used to obtain resistance against a wide range of plant viruses (reviewed in Gottula and Fuchs 2009). The resistance in plants that expressed viral $C P$ genes has been demonstrated to be RNA-mediated (Nomura et al. 2004) or protein-mediated (Powell et al. 1990, Srivastava and Raj 2008). The mechanism of resistance that occurs at the RNA level is believed to be RNA-RNA annealing between a transgene and viral transcripts after infection (Baulcombe 1996), resulting in the formation of dsRNA that induces PTGS. On the other hand, the mechanism of coat proteinmediated resistance was proposed to be the inhibition of virion disassembly in planta (Osbourn et al. 1989) or interaction with a nuclear inclusion protein-b, a replication protein in the infected cells (Hong et al. 1995). The use of RNAi-based approach in plants for establishing protection against a cognate virus was demonstrated against several cassava-infecting geminiviruses (Hong and Stanley 1996, Chellappan et al. 2004, Ntui et al. 2015).

Several plants have been engineered to express viralderived sense and antisense transcripts in order to restrict viral DNA accumulation upon infection (Kawchuk et al. 1991; Zhang et al. 2005). It was the first time where sense and antisense DNA constructs of SLCMV were used non-simultaneously in transgenic plants to induce resistance against a cognate virus. In the present study, transgenic $N$. benthamiana plants were engineered to express the SLCMV $C P$-sense or $C P$-antisense transcripts and conferred a significant protection against SLCMV. In particular, the $C P$-antisense lines exhibited a higher resistance as compared to the $C P$-sense lines at all 3 time points $(13,15,20 \mathrm{dpi})$ for the 1:625 agro-dilution, however, this difference was statistically not significant based on t-test analysis $(P<0.05)$. All four $C P$-antisense lines performed equally well in terms of resistance, whereas three out of four $C P$-sense lines gave a higher resistance compared to the $\mathrm{NbNt}$ infected plants. Moreover, a delay of symptom exhibition (3-5 days) was observed in both the $C P$-sense and the $C P$-antisense transgenic lines ( 7 out of 8 lines had asymptomatic plants at $10 \mathrm{dpi}$, Fig. 3).

To our knowledge, there are no direct comparisons published between agroinoculation and whitefly inoculation for geminivirus challenge experiments. Furthermore, no data are available on the amount of begomovirus transmitted by a single whitefly in the companion cells (phloem) of the host, which represents a very small fraction of the leaf cells. However, agroinoculation is considered as a high precision method of transgene insertion into the genome of plant cells interacting with Agrobacterium. Therefore, one can assume that a much greater fraction of plant cells are transformed (contain the virus genome) than companion cells. Rodríguez-Negrete et al. (2014) presented data of Tomato yellow leaf curl Sardinia virus (TYLCSV) accumulation - upon agroinoculation - at 3 dpi reaching to levels of $10^{7}$ virus particles per $200 \mathrm{ng}$ of total isolated DNA. Consequently, agroinoculation may introduce a much higher viral load than the natural means of geminivirus transmission with whiteflies.

Regarding the sense transgenic plants, we cannot distinguish whether the observed resistance is proteinor RNA-mediated, or both. The CP (protein)-mediated resistance has not been described for geminiviruses; further studies are needed starting with the detection of transgenically expressed $\mathrm{CP}$ in the sense lines upon the availability of SLCMV CP-specific antibodies. In contrast, the high resistance in the antisense transgenic lines is proposed to be RNA-mediated.

Regarding the RNA-mediated resistance, both sensePTGS (S-PTGS) and antisense-PTGS (AS-PTGS) have been suggested (Parent et al. 2015). It has been proposed that S-PTGS is based on the presence of aberrant antisense RNA molecules that, upon hybridization with the transgenically produced sense transcript, generate small quantities of dsRNA, which triggers RNAi requiring RDR6 for efficient amplification of siRNAs. Since in geminiviruses the transcription stops for the $\mathrm{L}$ and R-units have not been determined, we could not exclude that L-unit transcripts read-through towards the R-unit sequences, thus creating a template for hybridization of the transgenically produced sense transcript. In AS-PTGS, the mechanism proposed is the generation of high amounts of dsRNA molecules upon hybridization of the transgenically produced antisense transcript with, for example, the sense 
R-unit transcript in geminiviruses.

In the small RNA northern blot (Fig. 5), we observed a reduced accumulation of $C P$-specific vsiRNAs in the transgenic lines exhibiting resistance against SLCMV as compared to the non-transgenic plants, which correlates with the reduction of viral load in the transgenic lines upon SLCMV infection (Fig. 4). There are reports in literature suggesting that a high concentration of vsiRNAs in transgenic plants is correlated with RNA silencing against plant viruses (Kalantidis et al. 2002). However, it has been reported that RNAi could be functional even in cases where vsiRNAs are very low in amount or undetectable, and antiviral silencing is induced by e.g. hairpin constructs (a simultaneous expression of sense and antisense viral RNA) (Winterhagen et al. 2009, Ntui et al. 2015). In our study, sense and antisense RNAmediated SLCMV resistances were effective in spite of low levels of vsiRNAs.

In the small RNA northern blot, an increase in vsiRNA concentration was observed from 15 to 20 dpi in the antisense lines (Fig. 5A,B), which could be explained by the higher amount of dsRNA produced in AS-PTGS. We also observed a higher amount of vsiRNAs in the antisense lines as compared to the sense lines at 20 dpi (Fig. 5B). Based on the S-PTGS and AS-PTGS mechanisms, as mentioned above, the difference in vsiRNAs abundance between $C P$-sense and $C P$-antisense lines could be explained. We propose that such an elevated vsiRNA amount in $C P$-antisense lines could be a molecular marker of a more efficient RNAi against SLCMV.

An SLCMV resistant transgenic non-edible cassava cultivar has been developed using a hairpin construct with a $26 \%$ sequence homology to our designed constructs (Ntui et al. 2015). On the other hand, the present study demonstrates that sense and antisense RNA-mediated resistances made by the introduction of $C P$-sense or $C P$-antisense constructs in elite cassava cultivars could also be employed against SLCMV to obtain a high protection against a cognate virus. Our study strongly supports the use of the full-length SLCMV CP (AV1) gene for development of resistant cassava (edible and nonedible) cultivars against SLCMV. However, the antisense SLCMV CP construct should be likely preferred in field applications, due to a lack of production of a foreign (viral) protein in the plant host, as opposed to a full-length $C P$-sense construct. The potential risk of consuming a foreign protein from an engineered plant species cannot be ignored, and further study is required for better understanding with respect to human and animal health and for a definite conclusion.

\section{References}

Abel, P.P., Nelson, R.S., De B Hoffmann, N., Rogers, S.G., Fraley, R.T., Beachy, R.N.: Delay of disease development in transgenic plants that express the Tobacco mosaic virus coat protein gene. - Science 232: 738-743, 1986.

Alabi, O.J., Kumar, P.L., Naidu, R.A.: Cassava mosaic disease: A curse to food security in Sub-Saharan Africa. Online.
APSnet Features Online: 1-17, 2011.

Amudha, J., Balasubramani, G., Malathi, V.G., Monga, D., Kranthi, K.R.: Cotton leaf curl virus resistance transgenics with antisense coat protein gene ( $A V 1)$. - Curr. Sci. 101: 300307, 2011.

Aslam, U., Tabassum, B., Nasir, I.A., Khan, A., Husnain, T.: A virus-derived short hairpin RNA confers resistance against Sugarcane mosaic virus in transgenic sugarcane. - Transgenic Res. 27: 203-210, 2018.

Baulcombe, D.: RNA silencing in plants. - Nature 431: 356-363, 2004.

Baulcombe, D.C.: Mechanisms of pathogen-derived resistance to viruses in transgenic plants. - Plant Cell 8: 1833-1844, 1996.

Bejarano, E.R., Lichtenstein, C.P.: Expression of TGMV antisense RNA in transgenic tobacco inhibits replication of BCTV but not ACMV geminiviruses. - Plant mol. Biol. 24: 241-248, 1994.

Borah, B.K., Dasgupta, I.: Begomovirus research in India: A critical appraisal and the way ahead. - J. Biosci. 37: 791-806, 2012.

Chellappan, P., Masona, M.V., Vanitharani, R., Taylor, N.J., Fauquet, C.M.: Broad spectrum resistance to ssDNA viruses associated with transgene induced gene silencing in cassava. - Plant mol. Biol. 56: 601-611, 2004.

Chomczynski, P., Sacchi, N.: Single-step method of RNA isolation by acid guanidinium thiocyanate-phenol-chloroform extraction. - Anal. Biochem. 162: 156-159, 1987.

Curtin, S.J., Zsögön, A., Watson, J.M., Waterhouse, P.M.: Isolation and analysis of small RNAs from virus-infected plants. - Methods mol. Biol. 894: 173-189, 2012.

Dellaporta, S.L., Wood, J., Hicks, J.B.: A plant DNA minipreparation: Version II. - Plant mol. Biol. Rep. 1: 19-21, 1983.

de Haan, P.: Mechanisms of RNA-mediated resistance to plant viruses. In: Foster G.D., Taylor S.C. (ed.) Plant Virology Protocols. - Methods mol. Biol. 81: 533-546, 1998.

Dutt, N., Briddon, R.W., Dasgupta, I.: Identification of a second begomovirus, Sri Lankan cassava mosaic virus, causing mosaic disease in India. - Arch. Virol. 150: 21012108, 2005.

Fauquet, C.M., Briddon, R.W., Brown, J.K., Moriones, E., Stanley, J., Zerbini, M., Zhou, X.: Geminivirus strain demarcation and nomenclature. - Arch. Virol. 153: 783-821, 2008.

Fukunaga, R., Doudna, J.A.: dsRNA with $5^{\prime}$ overhangs contributes to endogenous and antiviral RNA silencing pathways in plants. - EMBO J. 28: 545-555, 2009.

Gogoi, A., Sarmah, N., Kaldis, A., Perdikis, D., Voloudakis, A.: Plant insects and mites uptake double-stranded RNA upon its exogenous application on tomato leaves. - Planta 246: 12331241, 2017.

Gottula, J., Fuchs, M.: Toward a quarter century of pathogenderived resistance and practical approaches to plant virus disease control. - Adv. Virus Res. 75: 161-183, 2009.

Haq, Q.M., Ali, A., Malathi, V.G.: Engineering resistance against Mungbean yellow mosaic India virus using Antisense RNA. Indian J. Virol. 21: 82-85, 2010.

Hong, Y., Stanley, J.: Virus resistance in Nicotiana benthamiana conferred by African cassava mosaic virus replication associated protein (AC1) transgene. - Mol. Plant Microbe Interact. 9: 219-225, 1996.

Hong, Y., Levay, K., Murphy, J.F., Klein, P.G., Shaw, J.G., Hunt, A.G.: A potyvirus polymerase interacts with the viral coat protein and VPg in yeast cells. - Virology 214: 159-166, 1995.

Hu, Q., Niu, Y., Zhang, K., Liu, Y., Zhou, X.: Virus-derived transgenes expressing hairpin RNA give immunity to Tobacco 
mosaic virus and Cucumber mosaic virus. - Virol. J. 8: 41, 2011.

Kalantidis, K., Psaradakis, S., Tabler, M., Tsagris, M.: The occurrence of CMV specific short RNAs in transgenic tobacco expressing virus-derived double stranded RNA is indicative of resistance to the virus. - Mol. Plant Microbe Interact. 15: 826-833, 2002.

Kawchuk, L.M., Martin, R.R., McPherson, J.: Sense and antisense RNA-mediated resistance to Potato leafroll virus in Russet Burbank potato plants. - Mol. Plant Microbe Interact. 4: 247-253, 1991

Leibman, D., Wolf, D., Saharan, V., Zelcer, A., Arazi, T., Yoel, S., Gaba, V., Gal-On, A.: A high level of transgenic viral small RNA is associated with broad potyvirus resistance in cucurbits. - Mol. Plant Microbe Interact. 24: 1220-1238, 2011.

Liu, D., Shi, L., Han, C., Yu, J., Li, D., Zhang, Y.: Validation of reference genes for gene expression studies in virus-infected Nicotiana benthamiana using quantitative real-time PCR. Plos ONE 7: e46451, 2012.

Mittal, D., Borah, B.K., Dasgupta, I.: Agroinfection of cloned Sri Lankan cassava mosaic virus DNA to Arabidopsis thaliana, Nicotiana tabacum and cassava. - Arch. Virol. 153: 21492155, 2008.

Murashige, T., Skoog, F.: A revised medium for rapid growth and bio assays with tobacco tissue cultures. - Physiol. Plant. 15: 473-497, 1962.

Nguyen, T.L.T., Gheewala, S.H., Garivait, S.: Full chain energy analysis of fuel ethanol from Cassava in Thailand. - Environ. Sci. Technol. 41: 4135-4142, 2007.

Nomura, K., Ohshima, K., Anai, T., Uekusa, H., Kita, N.: RNA Silencing of the introduced coat protein gene of Turnip mosaic virus confers broad-spectrum resistance in transgenic Arabidopsis. - Phytopathology 94: 730-736, 2004.

Ntui, V.O., Kong, K., Khan, R.S., Igawa, T., Janavi, G.J., Ranbindran, R., Nakamura, I., Mii, M.: Resistance to Sri Lankan cassava mosaic virus (SLCMV) in genetically engineered Cassava cv. KU50 through RNA silencing. - Plos ONE 10: e120551, 2015.

Nuwamanya, E., Chiwona-Karltum, L., Kawuki, R.S., Baguma, Y.: Bio-ethanol production from non-food parts of Cassava (Manihot esculenta Crantz). - Ambio 41: 262-270, 2012.

Osbourn, J.K., Watts, J.W., Beachy, R.N., Wilson, T.M.A.: Evidence that nucleocapside disassembly and a later step in virus replication are inhibited in transgenic tobacco protoplasts expressing TMV coat protein. - Virology 172: 370-373, 1989.

Parent, J.S., Jauvion, V., Bouché, N., Béclin, C., Hachet, M., Zytnicki, M., Vaucheret, H.: Post-transcriptional gene silencing triggered by sense transgenes involves uncapped antisense RNA and differs from silencing intentionally triggered by antisense transgenes. - Nucl. Acids Res. 43: 8464-8475, 2015.

Pathi, K.M., Tula, S., Tuteja, N.: High frequency regeneration via direct somatic embryogenesis and efficient Agrobacteriummediated genetic transformation of tobacco. - Plant Signal Behav. 8: e24354, 2013.

Patil, B.L., Fauquet, C.M.: Cassava mosaic geminiviruses: actual knowledge and perspectives. - Mol. Plant Pathol. 10: 685701, 2009.

Peláez, P., Sanchez, F.: Small RNAs in plant defense responses during viral and bacterial interactions: similarities and differences. - Front. Plant Sci. 4: 343. 2013.

Powell, P.A., Sanders, P.R., Tumer, N., Fraley, R.T., Beachy, R.N.: Protection against Tobacco mosaic virus infection in transgenic plants requires accumulation of coat protein rather than coat protein RNA sequences. - Virol. 175: 124-130, 1990.

Raj, S.K., Singh, R., Pandey, S.K., Singh, B.P.: Agrobacterium- mediated tomato transformation and regeneration of transgenic lines expressing Tomato leaf curl virus coat protein gene for resistance against TLCV infection. - Curr. Sci. 88 : 1674-1679, 2005.

Ramesh, S.V., Sahu, P.P., Prasad, M., Praveen, S., Pappu, H.R. Geminiviruses and plant hosts: A closer examination of the molecular arms race. - Viruses 9: 256, 2017.

Raza, A., Malik, H.J., Shafiq, M., Amin, I., Scheffler, J.A., Scheffler, B.E., Mansoor, S.: RNA interference based approach to down regulate osmoregulators of whitefly (Bemisia tabaci): Potential technology for the control of whitefly. - PLoS ONE 11: e0153883, 2016.

Rodríguez-Negrete, E.A., Sánchez-Campos, S., Cañizares, M.C., Navas-Castillo, J., Moriones, E., Bejarano, E.R., GrandePérez, A.: A sensitive method for the quantification of virionsense and complementary-sense DNA strands of circular single-stranded DNA viruses. - Sci. Rep. 4: 6438, 2014.

Sambrook, J., Fritschi, E.F., Maniatis, T.: Molecular cloning: a laboratory manual. - Cold Spring Harbor Laboratory Press, New York, 1989.

Saunders, K., Salim, N., Mali, V.R., Malathi, V.G., Briddon, R., Markham, P.G., Stanley, J.: Characterisation of Sri Lankan cassava mosaic virus and Indian cassava mosaic virus: evidence for acquisition of a DNA B component by a monopartite begomovirus. - Virology 293: 63-74, 2002.

Serio, F.D., Schob, H., Iglesias, A., Tarina, C., Bouldoires, E., Meins, F.Jr.: Sense- and antisense-mediated gene silencing in tobacco is inhibited by the same viral suppressors and is associated with accumulation of small RNAs. - Proc. Nat. Acad. Sci. USA 98: 6506-6510, 2001.

Shukla, A.K., Upadhyay, S.K., Mishra, M., Saurabh, S., Singh, R., Singh, H., Thakur, N., Rai, P., Pandey, P., Hans, A.L., Srivastava, S., Rajapure, V., Yadav, S.K., Singh, M.K., Kumar, J., Chandrashekar, K., Verma, P.C., Singh, A.P., Nair, K.N., Bhadauria, S., Wahajuddin, M., Singh, S., Sharma, S., Omkar, Upadhyay, R.S., Ranade, S.A., Tuli, R., Singh, P.K.: Expression of an insecticidal fern protein in cotton protects against whitefly. - Nature Biotechnol. 34:1046-1051, 2016.

Sohrab, S.S., Kamal, M.A., Ilah, A., Husen, A., Bhattacharya, P.S., Rana, D.: Development of Cotton leaf curl virus resistant transgenic cotton using antisense $\beta \mathrm{C} 1$ gene. - Saudi J. Biol. Sci. 23: 358-362, 2016.

Srivastava, A., Raj, S.K.: Coat protein-mediated resistance against an Indian isolate of the Cucumber mosaic virus subgroup IB in Nicotiana benthamiana. - J. Biosci. 33: 249257, 2008.

Thakur, N., Upadhyay, S.K., Verma, P.C., Chandrashekar, K., Tuli, R., Singh, P.K.: Enhanced whitefly resistance in transgenic tobacco plants expressing double stranded RNA of v-ATPase A Gene. - PLoS ONE 9: e87235, 2014.

Thresh, J.M., Otim-Nape, G.W., Legg, J.P., Fargette, D.: African cassava mosaic virus disease: The magnitude of the problem. - Afr. J. Root Tuber Crops 2: 13-19, 1997.

Thresh, J.M., Cooter, R.J.: Strategies for controlling cassava mosaic virus disease in Africa. - Plant Pathol. 54: 587-614, 2005.

Vanderschuren, H., Akbergenov, R., Pooggin, M.M., Hohn, T., Gruissem, W., Zhang, P.: Transgenic cassava resistance to African cassava mosaic virus is enhanced by viral DNA-A bidirectional promoter-derived siRNAs. - Plant mol. Biol. 64:549-557, 2007a.

Vanderschuren, H., Stupak, M., Fütterer, J., Gruissem, W., Zhang, P.: Engineering resistance to geminiviruses- review and perspectives. - Plant Biotechnol. 5: 207-220. 2007 b.

Wang, M.B., Masuta, C., Smith, N.A., Shimura, H.: RNA silencing and plant viral diseases. - Mol. Plant Microbe 
Interact. 25: 1275-1285, 2012.

Winterhagen, P., Dubois, C., Sinn, M., Wetzel, T., Reustle, G.M.: Gene silencing and virus resistance based on defective interfering constructs in transgenic Nicotiana benthamiana is not linked to accumulation of siRNA. - Plant Physiol. Biochem. 47: 739-742, 2009.

Yang, Y., Sherwood, T.A., Patte, C.P., Hiebert, E., Polston,
J.E.: Use of Tomato yellow leaf curl virus (TYLCV) Rep gene sequences to engineer TYLCV resistance in tomato. Phytopathol. 94: 490-496, 2004.

Zhang, P., Vanderschuren, H., Futterer, J., Gruissem, W.: Resistance to cassava mosaic disease in transgenic cassava expressing antisense RNAs targeting virus replication genes. - Plant Biotechnol. J. 3: 385-397, 2005. 